Article

\title{
Investigation of the Relationship between Rainfall and Fatal Crashes in Texas, 1994-2018
}

\author{
Zhongyu Han and Hatim O. Sharif * (B) \\ Civil and Environment Engineering, University of Texas at San Antonio, San Antonio, TX 78249, USA; \\ joeyhan2015@outlook.com \\ * Correspondence: hatim.sharif@utsa.edu; Tel.: +1-210-458-6478
}

Received: 22 August 2020; Accepted: 24 September 2020; Published: 26 September 2020

\begin{abstract}
Understanding how crash factors are impacted by rain is critical to road safety planning and management. This study assesses the impact of rain on traffic safety by conducting an analysis of the fatal crashes related to rain in Texas from 1994 to 2018. The fatal crash data was gathered from the Fatality Analysis Reporting System (FARS) database maintained by the National Highway Traffic Safety Administration (NHTSA). Environmental variables used in the analysis include month of the year, time of the day, temperature, and weather condition. The roadway-related factors identified include the posted speed limit, the number of lanes, route sign, and Vehicle Miles Traveled (VMT). The driver-related factors identified include age, gender, and the number of licensed drivers in total. Relative risk analysis was performed to statistically quantify the impact of rainy conditions at the hourly and monthly time scales. On average, rain-related fatal crashes represented about $6.8 \%$ of the total fatal crashes. However, the proportion shows higher variability at the annual, monthly, and hourly time scales and seems to be influenced by other factors such as the age and gender of the driver, type of the road, and posted roadway speed limit. Total and rain-related crashes show statistically significant decreasing trends when normalized by the total number of licensed drivers or vehicle miles travelled. The relative risk of a fatal crash during rainy conditions was always greater than 1.0 at hourly, monthly, and annual time scales. However, it shows significant variability at the monthly (1.07 to 2.78 ) and hourly scales (1.35 to 2.57$)$. The relative risk is higher in less urbanized and drier counties, in general. Gender and age analysis reveals that male and young drivers are more likely to be involved in a fatal crash but less likely to be killed in the crash.
\end{abstract}

Keywords: rainfall; hazards; fatal crashes; risk; Texas

\section{Introduction}

Transportation safety research is concerned with understating not only the crash factors but also the factors that influence crash severity. According to the World Health Organization (WHO), road traffic crashes kill approximately 1.35 million people around the world each year and injure between 20 and 50 million people [1]. There are serious concerns in the U.S. regarding the high number of fatal motor vehicle crashes in some states [2]. Moreover, traffic crashes are a leading cause of death in the U.S. and the leading cause of non-natural death for healthy U.S. citizens residing or traveling abroad [3]. In order to limit the number of fatal crashes, it is essential to identify and understand the main factors that lead to their occurrence [4]. There are numerous driver-related, vehicle-related, road-related, and environment-related factors that affect crash incidence and severity. Application of new data analytics and data mining techniques on large databases of crashes is one of the few robust methods to identify factors that increase the chances of a traffic crash [5]. However, traditional statistical methods are still widely used to determine the relationship between crashes and causal factors including correlation analysis and risk ratios. 
Several factors influence the driver's perception, such as light condition, surface condition [6], and road geometry [7]. Xu et al. (2013) examined traffic flow factors for clear, rainy, and reduced visibility conditions on interstate I-880N in California for 2008 and 2010 using Bayesian random intercept logistic regression models and found that speed difference between upstream and downstream stations had the greatest effect on crash risk [8]. Kim et al. (2020) examined the influence of road characteristics and traditional variables on teen driver's fatality and found that horizontal alignment, posted speed limit, traffic control, device type, and traffic way type are all statistically significant factors affecting crash fatalities [9]. Unrau and Andrey (2006) studied a driver's response to light precipitation on urban expressways [10]. Adverse weather conditions are important factors affecting traffic fatalities and are reported as a factor in a large number of motor vehicle fatalities in the U.S. [11]. These adverse conditions include rain, snow, cloudy conditions, fog, and wind. Such weather conditions can affect the likelihood of road traffic injury and fatality occurrence in multiple ways, such as through decreased visibility, increased stopping distance, and wet road surfaces that lead to hydroplaning and loss of vehicle control [11,12]. Pisano et al. (2008) estimated that $25 \%$ of all crashes that occurred on public roads in the U.S. were related to weather [13]. According to recent analyses, weather was a cause or contributing factor in $35 \%$ of fatal crashes [14]. Hayat et al. (2013) found a significant correlation between adverse weather conditions and crash injury in a 20-year study [15]. Using geo-spatial statistical analysis, Khan et al. (2008) found the characteristics of weather-related crashes to be spatially correlated with the patterns of weather conditions such as rain, snow, and fog [16]. Using the same approach, Sharif (2016) found spatial correlation between rainfall and crash frequency in Texas [17]. Qiu and Nixon (2008) found that snowfall could increase the crash rate by $84 \%$ and the injury rate by $75 \%$ [18]. Andrey et al. (2003) found a 75\% increase of traffic during wet conditions in some case studies [19]. Sun et al. (2011) conducted a similar research that quantified the effect of adverse weather on crash risk using radar rainfall data and the matched-pair method [20]. They found rain to cause a higher risk of crash occurrence and severity. Hambly et al. (2013) observed the most serious crash impacts when the daily rainfall amount is larger than $10 \mathrm{~mm}$ [21]. El-Basyouny et al. (2014) demonstrated how rain is significantly and positively correlated with all crash types [22].

Crash frequency analysis is used to develop traffic management practices. For example, Milton et al. (2008) examined statistical analysis techniques used to model crash rates for transportation safety maintenance [23]. They found several factors associated with traffic conditions. Anastasopoulos and Mannering (2009) examined count data statistical methods for forecasting crash frequency using random-parameter count models [24]. They identified that a variety of factors relating to pavement condition and quality were found to significantly influence vehicle accident occurrences. Depaire et al. (2008) examined similar crash datasets and their results indicated that the traffic crash types and their clustering patterns added value to subsequent crash outcome analyses and were most appropriate for identifying hidden relationships [25]. Matkan et al. (2013) studied the spatial-temporal autocorrelation by examining the crash frequencies in urban areas and found crashes occurred not only through clustering in the same location but also within a specific time range [26].

Several studies evaluated weather impacts on crashes and their severity used single and multivariate statistical analysis [27-33]. For example, Edwards [29] examined the spatial distribution of weather-related crashes in England and Walesand found a positive relationship between the incidences of weather hazards and road crashes. An analysis by Andreescu and Frost [30] also confirmed a significant positive correlation between precipitation and the number of crashes at daily time scale in Montreal, Canada. Sangare et al. [31] developed a prediction model that combines a Gaussian Mixture Model (GMM) and a machine learning algorithm to identify road segments that are most prone to crash incidence base on factors related to the driver, vehicle, and the environment. The model successfully identified high risk road segments in most of the cases. Oralhan and Goktolga [32] found that the severity of traffic crashes was mostly influenced by the driver's gender, age, and education level, in addition to the number of vehicles involved in the accident, road surface material, daylight, type of road, direction of road, and time of the day. Benlagha and Charfeddine [33], using a large sample of 
405,177 crashes and various statistical and econometrics approaches, found that the gender factor is only significant for fatal accidents with male drivers having an increased likelihood of extreme risk behavior. Abdel-Aty and Pande (2006) recommended considering weather conditions, more importantly rain occurrence, in evaluating the factors associated with crashes [34]. Ma et al. (2009) analyzed thousands of crashes and identified roadway geometry, crash location, roadway alignment on tangents and curves, roadway functional classification, and lighting condition as significant crash-related factors while Ma et al. (2011) found statistically significant factors related to crash severity to be location, weather, driver's gender, vehicle type, and crash type [35,36]. Jung et al. (2010) found the most important factors to be rainfall intensity, wind speed, roadway terrain, drivers' gender, and seat belt [37]. Wilson and Stimpson (2010) investigated the trends in distracted driving fatalities and found that more crashes involved male drivers than females in urban areas [38]. Lira et al. (2020) found alcohol involvement to be a very significant factor affecting crashes [39]. Jovanis and Chang (1986) showed environmental conditions to be a major factor proved to affect automobiles more than trucks [40]. Amoros et al. (2003) found a statistically significant relationship between crashes, roadway classification, and county [41]. Abdel-Aty et al. (1999) found a potential relationship between driver age and factors related to crash involvement including crash location, type of collision, roadway characteristics, speed of vehicles prior to crash, roadway surface conditions, and light conditions [42]. Yan et al. (2020) found atmospheric conditions, crash time, alcohol usage, crash type, and driver's distraction affect the injury severity of crashes [43].

Although several studies address the impact of weather on traffic safety, none of them presented a detail analysis at different temporal and spatial scales over a multi-decadal period while considering other factors such as age and gender. Since it leads the U.S. in fatal crashes, there is a need for more in-depth analysis of the main factors that contribute to fatal crashes in Texas. This study aims to assess and quantify the impact of rain on traffic safety in Texas by investigating all fatal crashes that occurred under rainy conditions in Texas from 1994 to 2018. The fatal crash data was gathered from the Fatality Analysis Reporting System (FARS) database maintained by the National Highway Traffic Safety Administration (NHTSA). A detailed descriptive statistical analysis of rain-related fatal crashes was performed at the state level. These rain-related fatal crash factors were also categorized and examined at the state level. Environmental variables used in the analysis include month of the year, time of the day, light condition, temperature, and weather condition. The roadway-related factors identified include the posted speed limit, the number of lanes, route sign, and Vehicle Miles Traveled (VMT). The driver-related factors identified include age, gender, and the number of licensed drivers in total. Relative risk analysis was performed to statistically quantify the impact of rainy conditions at the hourly and monthly time scales.

\section{Methodology}

The most comprehensive source for fatal vehicle crash data in the United States is the FARS maintained by the NHTSA. The FARS system records data for crashes that occur on public roads in the United States from a variety of sources including police reports, vital statistics, death certificates, hospital medical records, and emergency medical or coroner reports [38,44]. For this study, files were downloaded from the FARS website for the period of 1994 to 2018. The data record also contains numerous independent variables such as weather conditions, date, time, exact crash location, gender of drivers, weather condition, and time of crashes. The database lists thirteen possible weather-related variables associated with crash occurrence including clear; rain (mist); hail (freezing rain or drizzle); snow, fog smoke, or severe crosswinds; blowing sand; sand; soil; dirt; other; cloudy; blowing snow; not reported; and unknown. Other data sources include the National Centers for Environmental Information (rainfall and temperature); the Texas Department of Transportation (TxDOT) Crash Record Information System (CRIS) for cross checking of the FARS fatality data; the U.S. Department of Transportation, Federal Highway Administration for annual and monthly VMT data; and the population of Texas was obtained from the United States Census Bureau. 
The data was downloaded for each year and then combined as the data format has changed over time. R scripts were developed to extract relevant variables needed for the analysis. Excel was used to compute Pearson correlation coefficients. R scripts were used to run Mann-Kendall nonparametric trend analysis. Excel was used to perform analysis of variance (ANOVA) to compare variables such as the gender differences and the monthly distributions of total and rain-related fatalities. $R$ scripts were used to process rainfall data and compare rain and no-rain periods in terms of fatality counts (matched pair analysis).

\section{Results}

\subsection{Temporal Distribution of Fatal Crashes}

The FARS database reported a total of 78,069 fatal crashes in Texas between 1994 and 2018, among which 5344 crashes (6.9\%) occurred during rainy conditions (rain-related). To qualify as a fatal crash, the crash must have occurred on a public road and a related death must have occurred within 30 days of the crash. During this 25 -year period, there was an average of approximately 214 rain-related fatal crashes per year. Figure 1 shows the annual distribution of the total and rain-related fatal crashes for Texas over the study period. The number of annual rain-related fatal crashes varies from a low of 114 in 2011 (driest year in recent records) to a high of 339 in 2004, while the number of total crashes ranged from 2746 in 2010 to 3427 in 2016. The annual variability is high and there is no clear trend in the annual totals for both time series. It can also be observed that there is no similarity in the annual patterns of the two series. Figure 2 shows the fatal crashes comparison between CRIS and FARS. The number of crashes in the databases is almost identical, with CRIS being only slightly higher than FARS over the study period, which can be attributed to lapses in the reporting. Numbers of rain-related crashes are also almost identical in the two databases.

A better test of annual trends can be performed when indicators of the real exposure (cars on the road), which can change from year to year, are used to normalize the fatalities. When the total population of Texas is considered as a proxy for the number of vehicles on Texas roads and used to normalize the number of fatal crashes and rain-related fatal crashes (Figure 3), the data shows that both total and rain-related crashes have statistically significant decreasing trends over the study period with $p$-values of 0.001 , and 0.004, respectively based on the Mann-Kendall nonparametric trend test. The two time series show similar decreasing trends (Figure 4) when the annual fatalities are normalized by the Vehicle Miles Traveled (VMT) in Texas, as another indicator of the exposure. The Man-Kendall nonparametric test also confirms statistically decreasing trends for VMT-normalized total and rain-related crashes with $p$-values of 0.001 , and 0.006 , respectively.

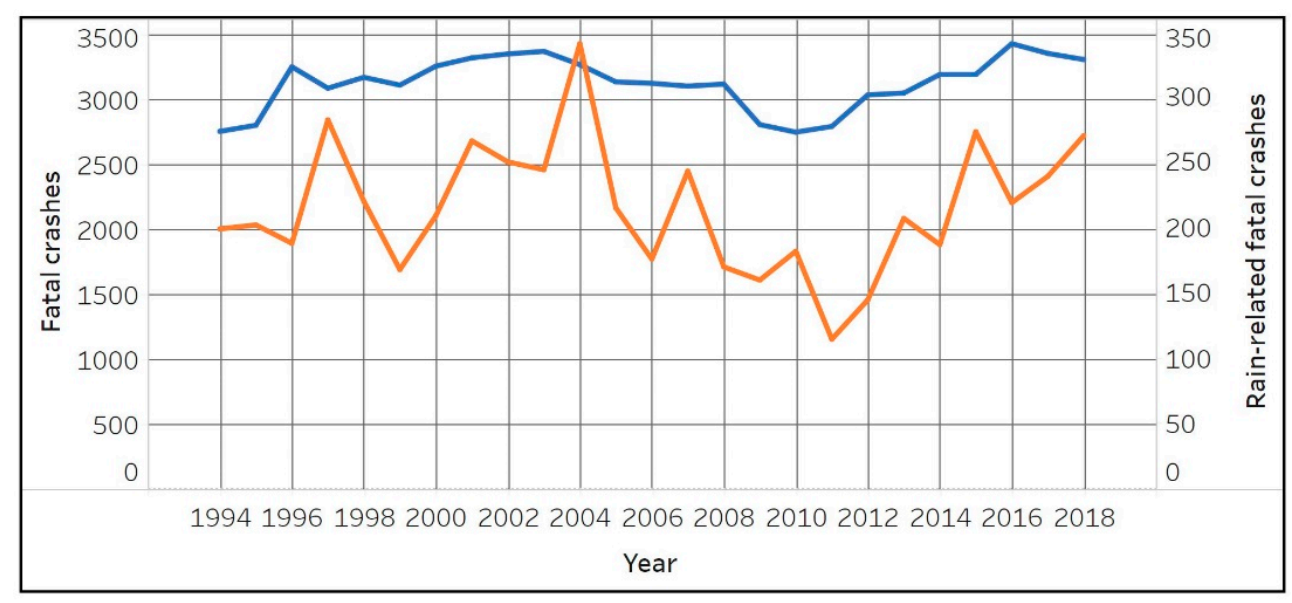

Fatal crashes

- Rain-related fatal crashes

Figure 1. Annual distribution of total and rain-related fatal crashes in Texas, 1994-2018. 


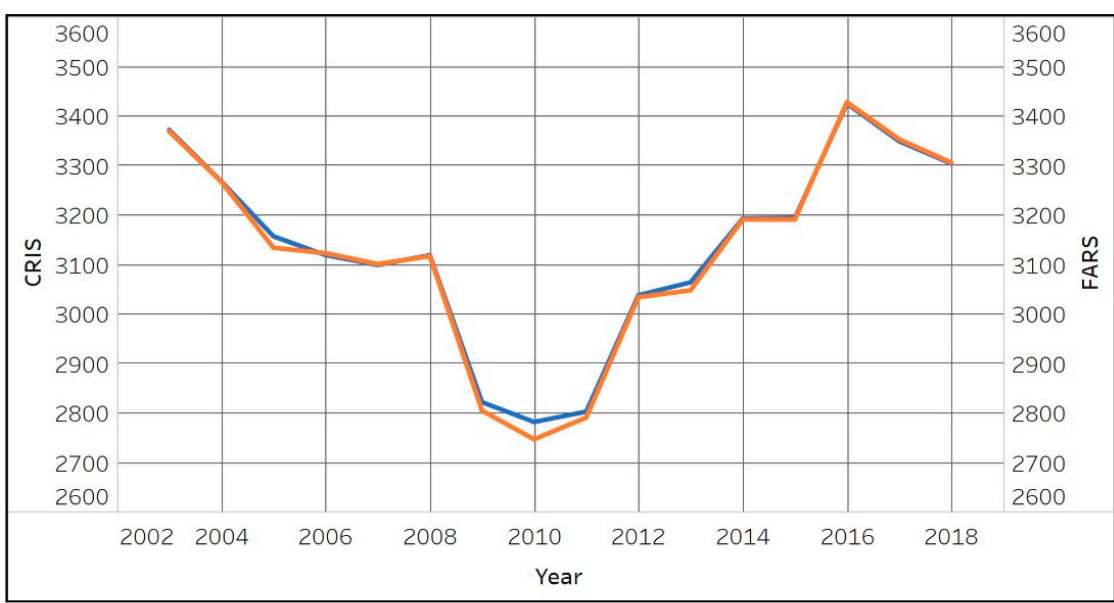

- CRIS

FARS

Figure 2. Fatal crashes from Crash Record Information System (CRIS) and Fatality Analysis Reporting System (FARS), 2003-2018, Texas.

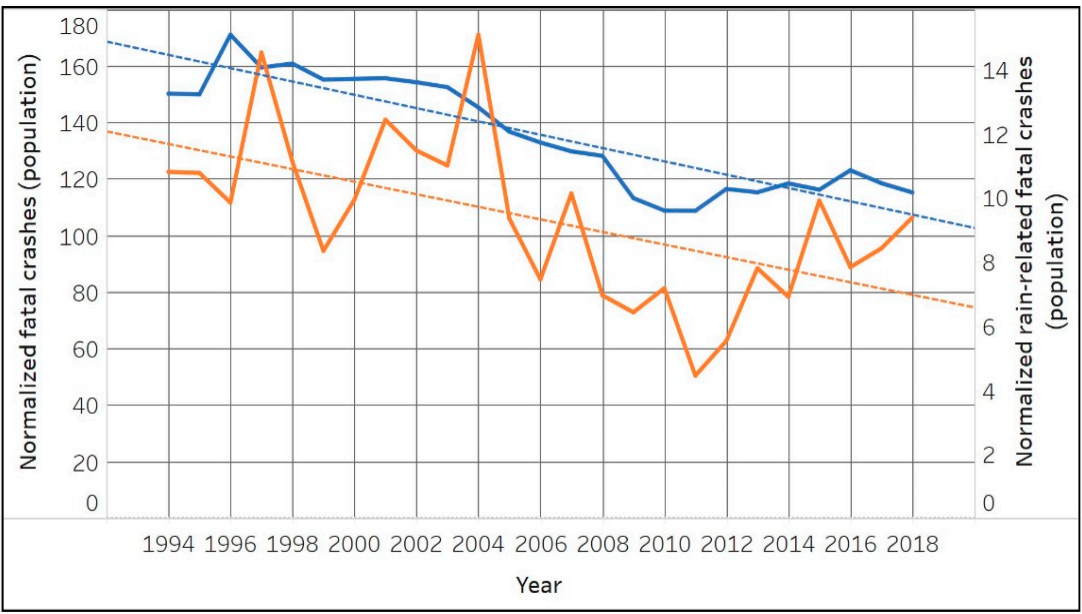

Normalized fatal crashes by population

normalized rain-related fatal crashes by population

Figure 3. Fatal crashes and rain-related fatal crashes normalized by Texas population (per million), 1994-2018.

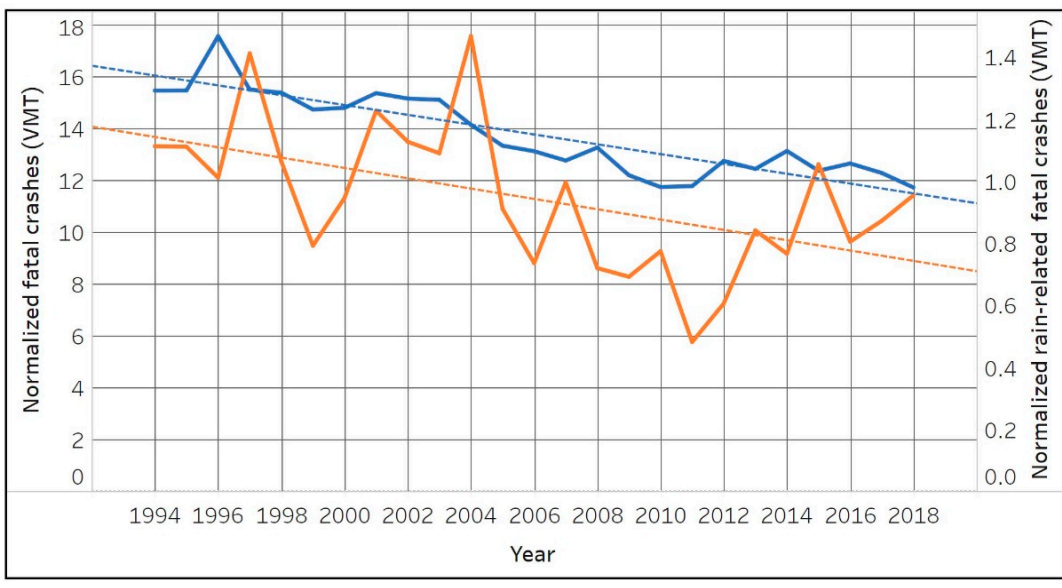

- Normalized fatal crahes by annual VMT

- Normalized rain-related fatal crashes by annual VMT

Figure 4. Annual total crashes and rain-related fatal crashes normalized by Vehicle Miles Traveled (VMT) (billions) in Texas, 1994-2018. 
The monthly distributions of the rain-related fatal crashes and total fatal crashes are shown in Figure 5. The monthly distributions of the two series are quite different. While the numbers of total fatal crashes stay steady, the rain-related crashes show a strong seasonality with significantly smaller numbers in the summer months. The monthly total (over the 25-year period) of rain-related crashes fluctuates between 290 crashes that occurred in July and 645 crashes in December. The months from October to March, except February, all have a total of more than 500 rain-related fatal crashes. To statistically test the differences in monthly distributions for total and rain-related crashes, we performed one-way ANOVA for the monthly proportion of crashes for each month for all years and found significant differences in the proportions for all 12 months at significance level of 0.05 . R scripts were used to process rainfall data and match fatality counts for rain and no-rain periods (match pair analysis).

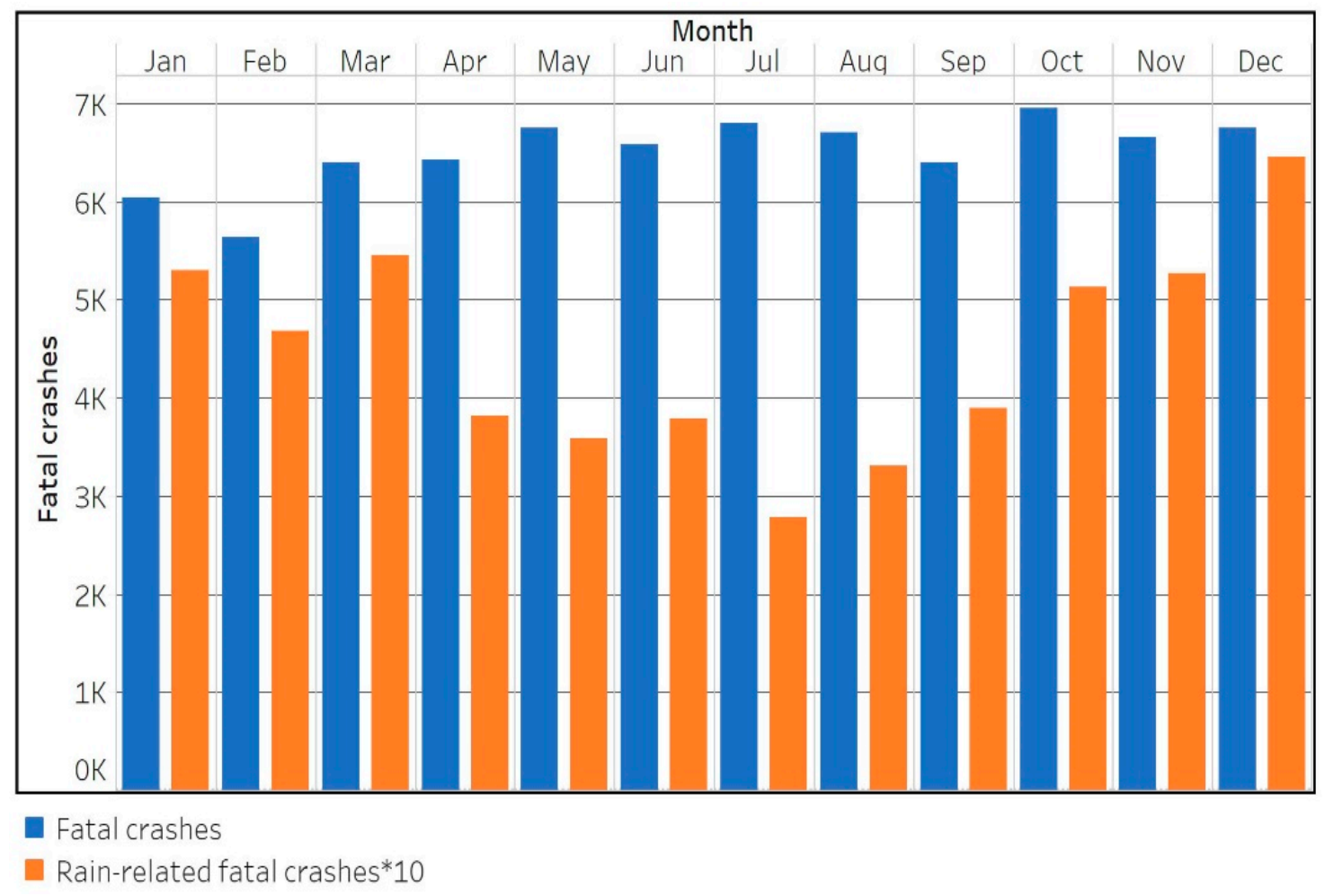

Figure 5. Monthly distribution of rain-related and total fatal crashes (numbers of rain-related crashes are multiplied by 10).

Total fatal crashes were also compared to rain-related fatal crashes at the hourly time scale (Figure 6). Both time series show three distinct peaks: 2:00-3:00 a.m. (bars close at 2:00 a.m. in Texas) and two peaks associated with the regular traffic peaks (morning and evening). The morning peaks coincide in the two series; however, the afternoon peak is delayed in the total crashes series, probably due to the effect of visibility during the dark hours. As seen in Figure 6, the third hour of the day is when the most hourly fatal crashes (4772) occur while the 18th h of the day is the hour when most rain-related fatal crashes (286) occur. Both time series have a significant dip in the number of crashes during the fifth and 10th $h$ of the day. 


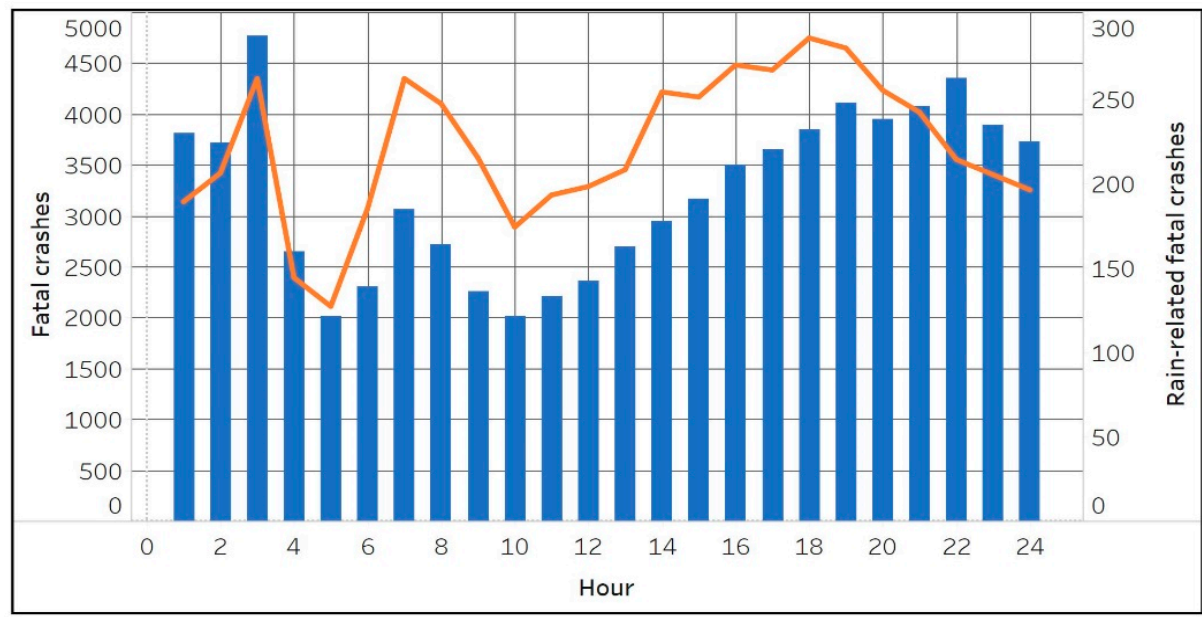

- Fatal crashes

- Rain-related fatal crashes

IIme

(a)

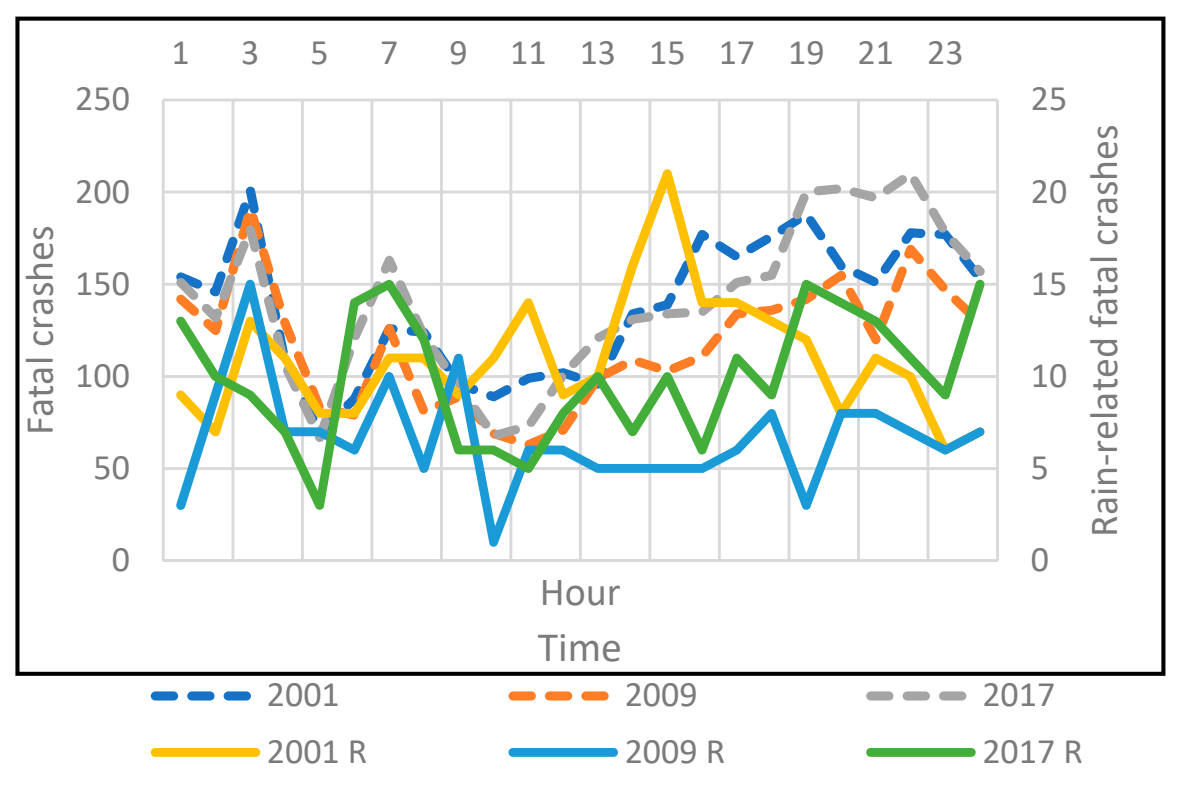

(b)

Figure 6. Hourly time distribution of fatal crashes (a) with examples showing the year-to-year variability (b).

The differences between the two series can also be seen in Figure 7 when the hourly data is grouped into four equal periods. The amount of rain-related fatal crashes has been multiplied by 10. Most of the total fatal crashes, 24,137 or $31 \%$ of total, occurred during the 6 p.m. -12 a.m. period, while most rain-related fatal crashes, 1536 or $29 \%$, occurred between 12 p.m. -6 p.m. The difference between the total and rain-related crashes is much higher during the dark hours than during day hours. 


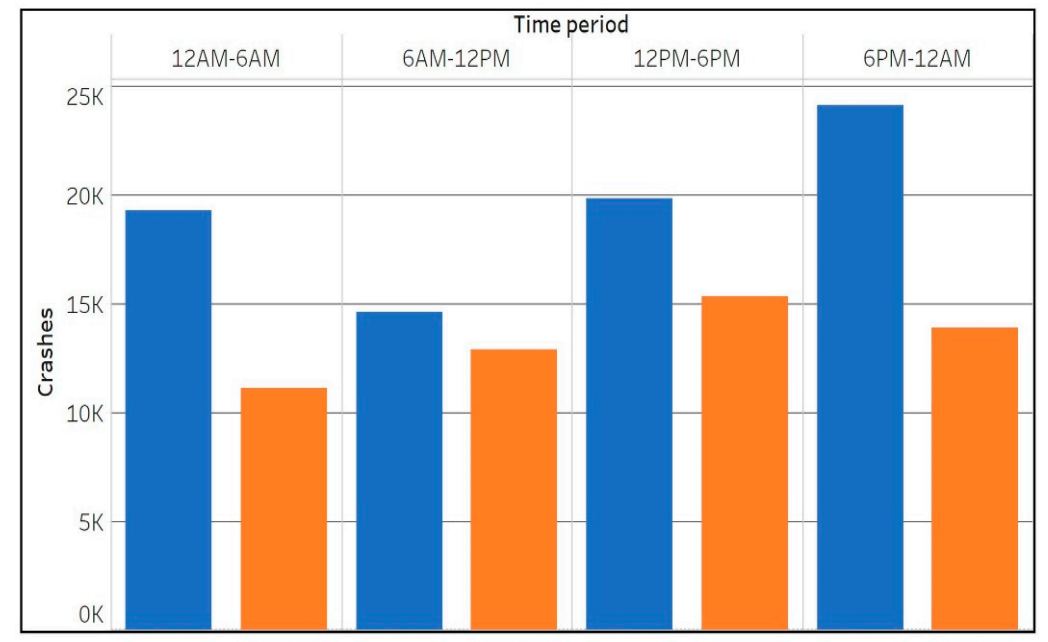

- Fatal crashes

Rain-related fatal crashes*10

(a)

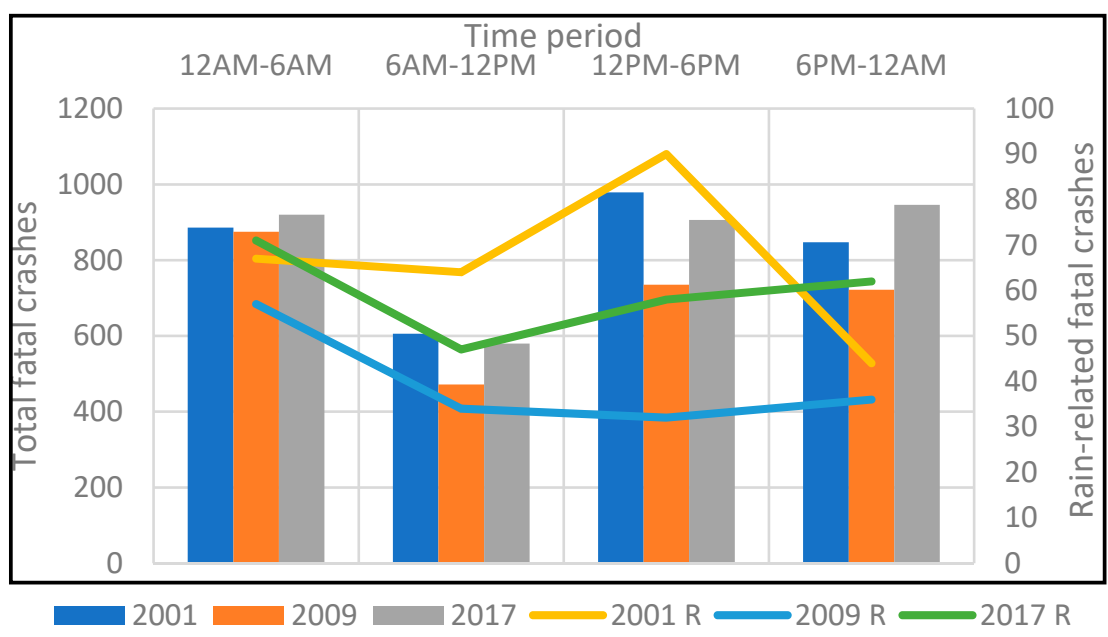

(b)

Figure 7. Distribution of fatal crashes over the four daily time periods (a) with examples showing the year-to-year variability $(\mathbf{b})$.

\subsection{Age and Gender}

The age and gender classification of the driver involved in total and rain-related fatal crashes are shown in Figures 8 and 9, respectively. The data was normalized by the number of licensed drivers among each group in 2006, the midpoint year of the study period. Both figures show that much more male drivers are involved in fatal crashes than female drivers for all age groups. ANOVA test results showed that, for all ages, there was a difference between males and female with a $p$-values of less than 0.01 . Nationally, the crash rate (fatal or non-fatal) is significantly lower for female drivers for all age groups [45] as males are more likely to be involved in risky behavior [46]. Overall, male drivers are about 2.85 times more likely to be involved in a fatal crash than female, which is higher by $10 \%$ than the ratio for rain-related fatal crashes (2.57). This $10 \%$ difference also suggests that females are less likely to drive during inclement weather. Young male and female drivers (age under 25 years) are more likely to be involved in fatal crashes for both crash categories, followed by male and female 
drivers in the 25 to 34 year age group. Drivers between 65 and 74 years old are the least likely to be involved in fatal crashes for both crash categories. There are slight differences in the distribution of fatal crashes for different age groups involved in the two crash categories.

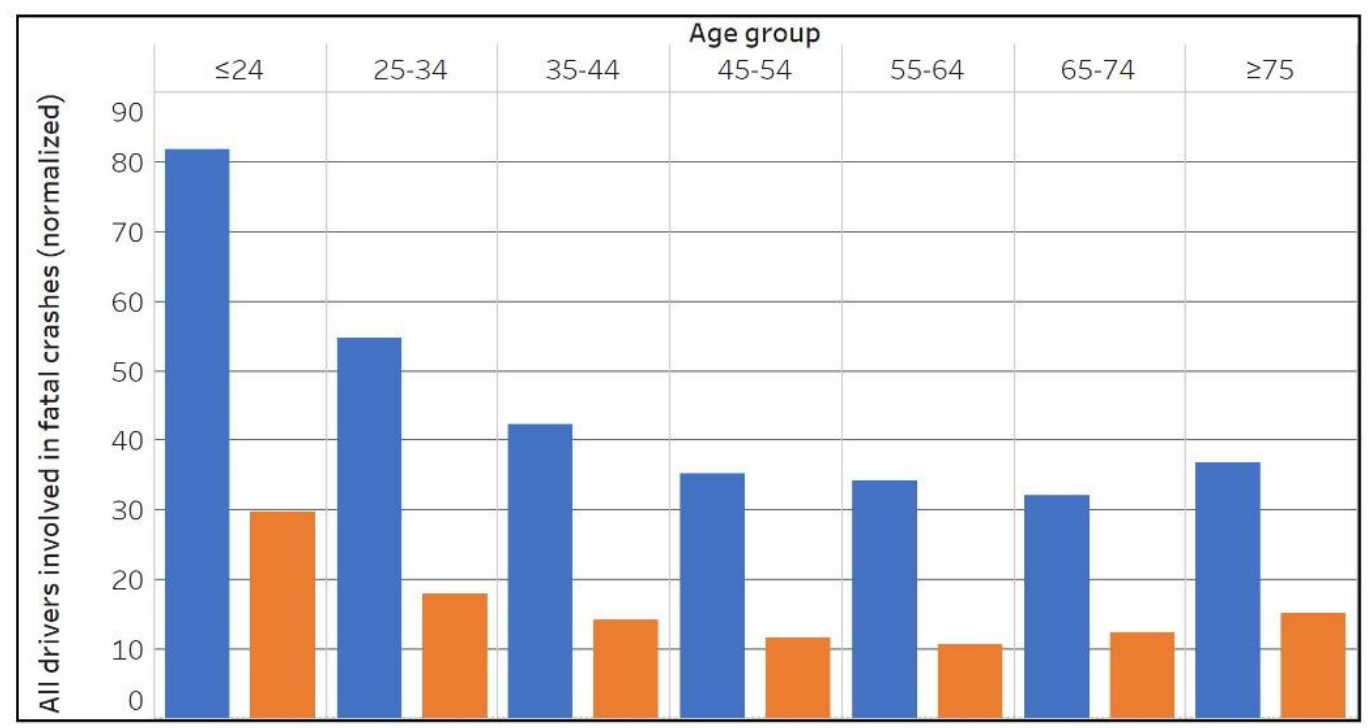

Male

Female

(a)

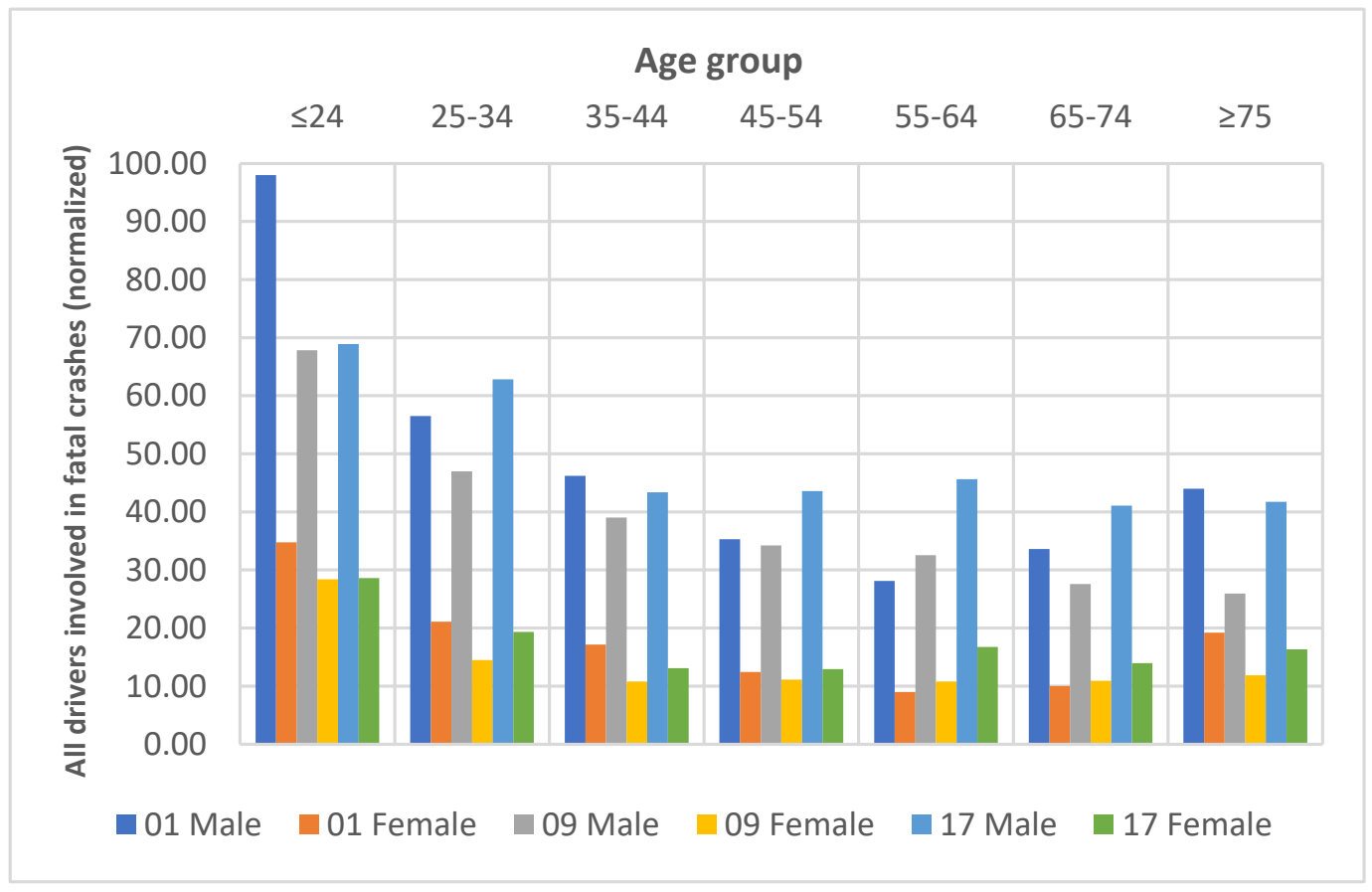

(b)

Figure 8. Driver age and gender classification for total fatal crashes normalized by the number of licensed drivers (a) with examples showing the year-to-year variability (b). 


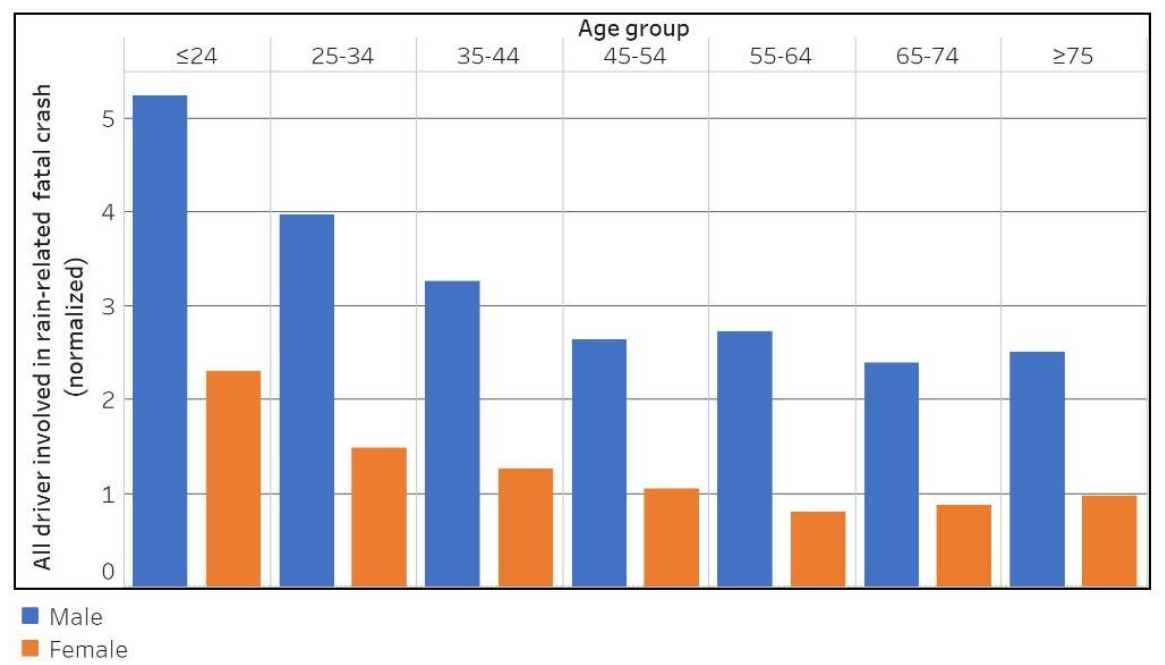

(a)

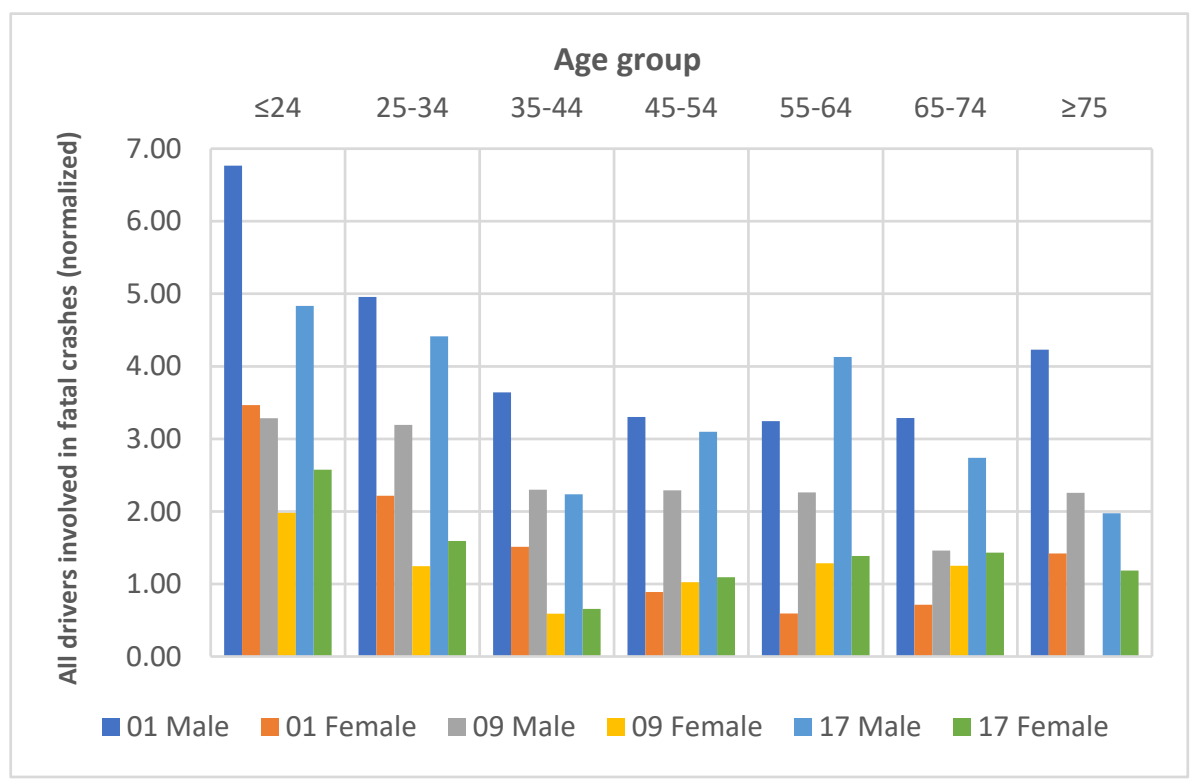

(b)

Figure 9. Driver age and gender classification for rain-related fatal crashes normalized by the number of licensed drivers (a) with examples showing the year-to-year variability (b).

Forty-six percent of the drivers involved in total fatal crashes were killed-in a large number of crashes, the victim is not the driver. The percentage is slightly higher $(48 \%)$ for rain-related fatal crashes. The age and gender distribution of drivers killed in all fatal crashes normalized by the number of driver license holders is shown in the Figure 10. Again, for all ages, the one-way ANOVA test confirms that there is a difference between males and female with a $p$-values of less than 0.01.Young drivers have the highest proportion for both males and females. The figure shows that killed male drivers significantly outnumber female drivers for all age groups. However, the distribution is different from that of Figure 8. The age group of 45 to 54 has the lowest number of killed drivers for both male and female. The numbers increase for drivers older than 54 indicating the increased risk of death for older drivers. Another difference between Figures 8 and 10 is the proportion of females is slightly higher 
in Figure 10. This agrees with studies that found that although crashes involving male drivers are often more severe than those involving female drivers, females are more likely to be killed or injured in crashes of equal severity (e.g., [46]). National data also indicated that older drivers are more likely to be killed or injured (e.g., [47]). The age and gender distribution of drivers killed in rain-related fatal crashes is similar to the one shown in Figure 10.

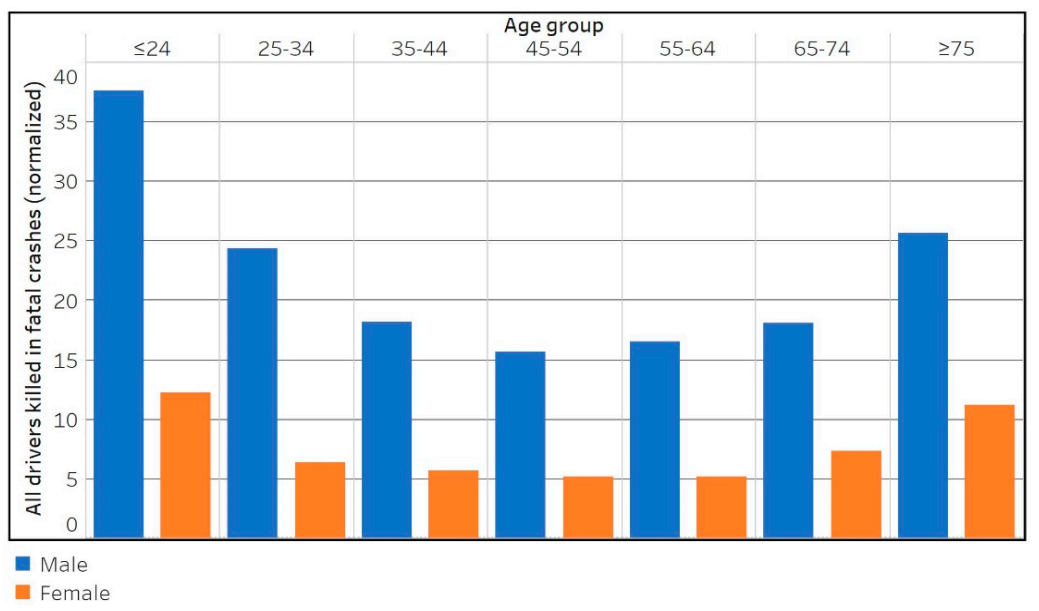

Figure 10. Age and gender classification of drivers killed in the fatal crashes for total fatal crashes normalized by average number of licensed drivers.

\subsection{Rainfall Influence}

The annual distribution of the proportion of rain-related fatal crashes is shown in Figure 11 together with the annual statewide average precipitation of Texas over the study period. The two time series are strikingly similar with a correlation of 0.84 . The proportion ranges from a low of $4.1 \%$ of total fatal crashes in 2011 (driest year) and a high of 10.4\% f in 2004 (second wettest year).

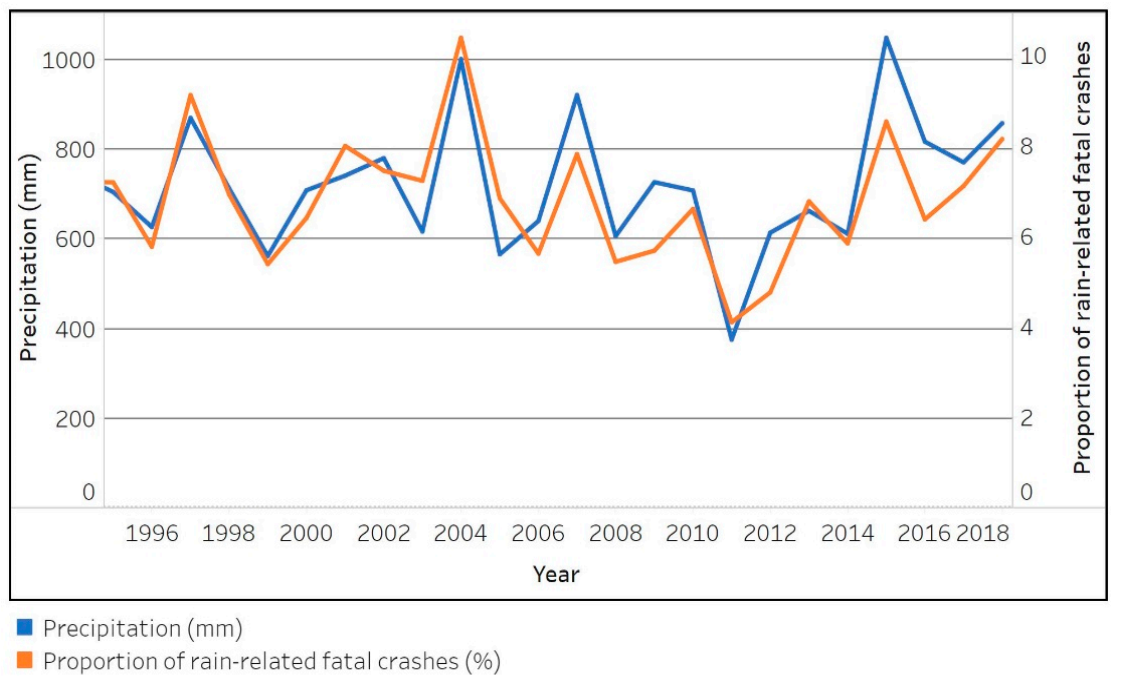

Figure 11. Annual distribution of the proportion of rain-related fatal crashes and the statewide average precipitation.

Figure 12 shows the monthly distribution of the proportion of rain-related fatal crashes to statewide average monthly precipitation temperature of the study period. The monthly distribution of rainfall shows that the peak rainfall occurs in March, May, September, and October, with the lowest amounts recorded in December, January, and February. Interestingly, the rain-related fatal crashes show an almost opposite trend at the monthly time scale, unlike the annual trends. The correlation test reveals 
a negative correlation of -0.66 between monthly fatal rain-related crashes and rainfall averages for the month. This can be explained by the effect of temperature, with evaporation cancelling the effect of rainfall during the summer (e.g., [48]). Moreover, cooling of hot road surfaces by rainfall in the summer has a positive effect on the frictional properties of the surface [49]. Negative correlation with temperature is extremely high at -0.94 . The relationship between temperature and precipitation was further investigated using multiple regression analysis. The analysis reveals that temperature and precipitation explains more than $92 \%$ of the variability in the proportion of rain-related crashes, with temperature having a negative coefficient and precipitation having a positive coefficient.

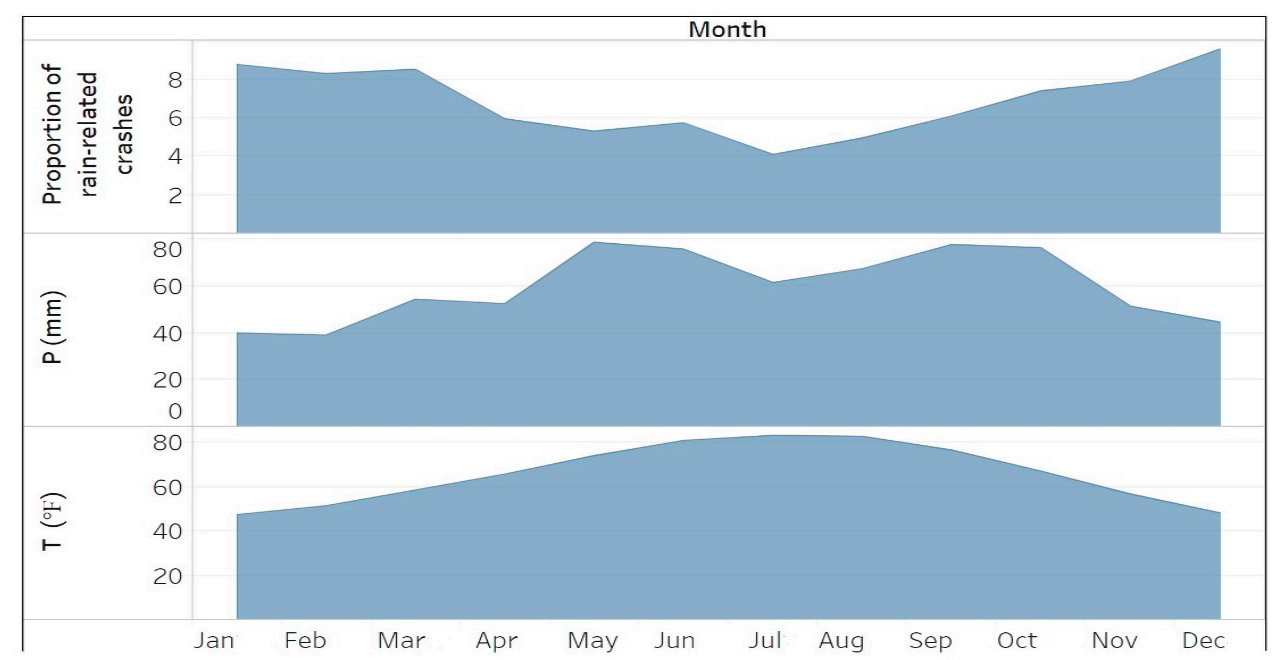

Figure 12. Monthly distribution of the statewide precipitation, temperature, the proportion of rain-related fatal crashes.

\subsection{Relative Risk during Rainy Conditions}

The relationship between precipitation and fatal crashes can be statistically quantified by calculating the relative risk of a fatal crash during rainy condition compared to dry conditions. The relative risk represents the ratio of the probability of a fatal crash during rainy conditions (pr) to the probability of a fatal crash during dry conditions (pd). This can be approximated by comparing the rate of fatal crashes that occur during rainy and dry hours while making sure that hours are compared during similar traffic, e.g., crash rates during rainy conditions at peaks hour are compared to those during dry conditions at the same hours. We assume that performing the comparison at hourly, monthly, and annual time scales can significantly reduce the effect of other risk factors such as random driver behavior, and traffic volumes. For that purpose, we compiled Stage IV weather radar data at hourly temporal resolution, integrated from the 5-6 min native products, and a spatial resolution of $4 \mathrm{~km}$ covering the entire state of Texas starting from 2002 to 2018-radar data was not complete during the previous years. The data was obtained from the National Centers for Environmental Prediction (NCEP) website (https://www.emc.ncep.noaa.gov/mmb/ylin/pcpanl/stage4/). Detailed description of the Texas radar data is provided by Ghebreyesus and Sharif (2020) [50].

The hourly relative risk (Figure 13a) varies between 1.3 (30\% higher risk of a fatal crash during rainy conditions) between 9 and 10 p.m. to 2.6 between 8 and 9 a.m. The distribution indicates that the relative risk is affected more by traffic volumes (day hours) than by visibility (night hours) but the effect of temperature discussed above can be seen in the decreased relative risk during the afternoon rush hours. Day and night bring different hazards, with nighttime resulting in decreased visibility but also decreased traffic density. This agrees with findings reported by Black and Mote (2015) [51] and Stevens et al. (2019) [52]. The effect of temperature can be clearly seen in the monthly distribution of the relative risk (Figure 13b), which varies between around 1.0 (no added risk during rainy conditions) in July to more than 2.8 in December. The freezing conditions during the winter months (not widely common in 
Texas) can also be a factor (e.g., [18]) The relative risk also varies from year to year with a minimum of 1.2 (2014) to a maximum of 2.6 (2003). The variability is not related to the annual precipitation (Figure 11) but the monthly distribution within a given year. For example, the relative risk is high for 2011 (the driest year) because the winter months were relatively drier than the summer months. The reverse can be observed in 2015 with a very wet, record-breaking summer and early fall months.

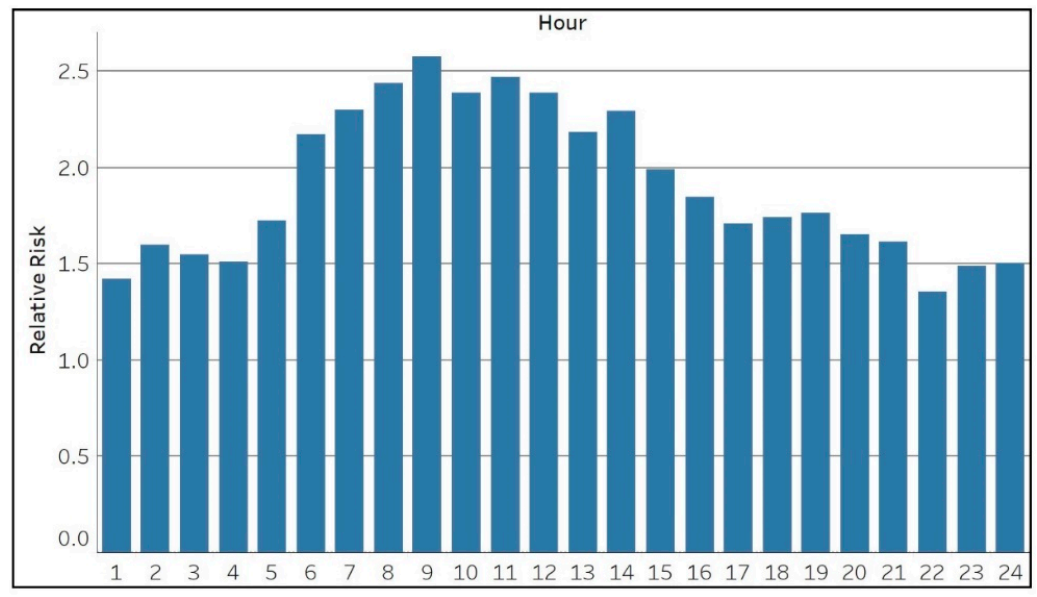

(a)

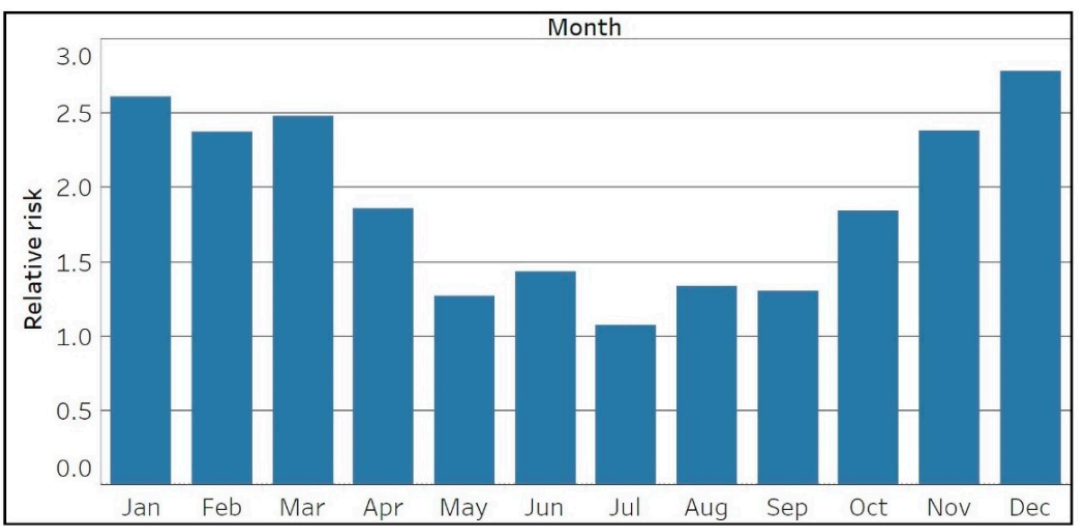

(b)

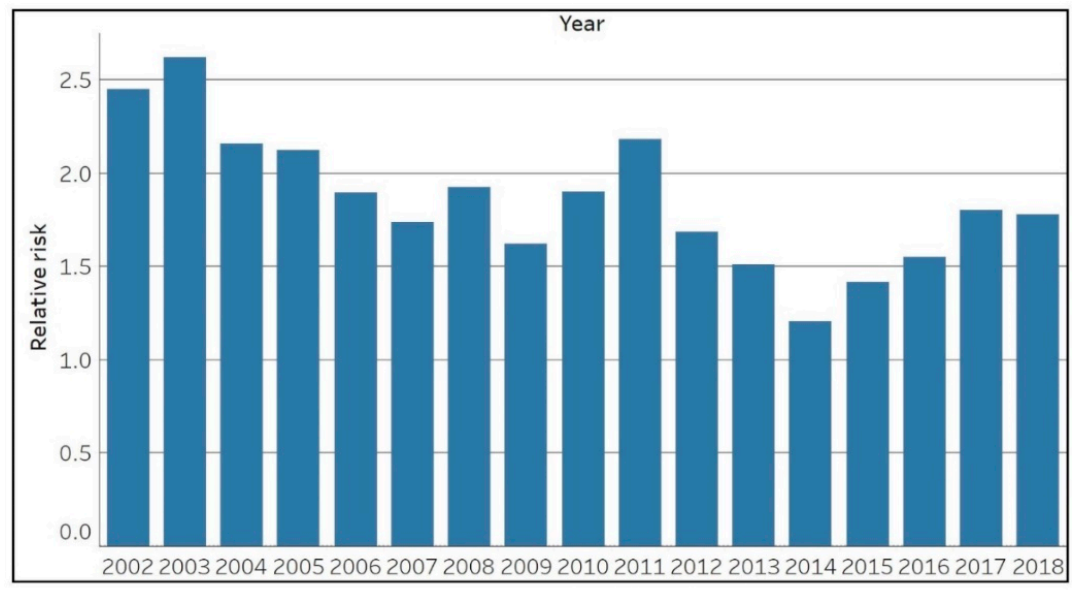

(c)

Figure 13. Relative crash risk under rainy conditions at (a) hourly, (b) monthly, and (c) annual time scales. 


\subsection{Spatial Distribution of Crashes}

The spatial distributions of total crashes are shown in Figure 14 for crashes that occurred since 2001 as coordinates are not available for earlier crashes. Crashes are clustered around major metropolitan areas such as Houston, Dallas-Fort Worth, San Antonio, and Austin metropolitan areas-predominantly in the high-density center of each city-and along major freeways. More than $90 \%$ of the fatal crashes occurred around or east of Interstate Highway I-35. This is expected as more than $87 \%$ of Texans reside in this part of Texas according to the state's Demographic Center [53]. This part of Texas also receives much higher amounts of rainfall compared to the western part [50]. The spatial distribution of rain-related fatal crashes is similar as can be seen in Figure 14. The crashes are aggregated at the county level in Figure 15 for the 1994-2018 period. The top highly urbanized counties of Texas, Harris (City of Houston), Dallas (Dallas), Bexar (San Antonio), Tarrant (Fort Worth), and Travis (Austin), account for $30.5 \%$ of the total fatal crashes and $30.0 \%$ of the rain-related crashes. Respectively, these counties witnessed 8809 (561), 5592 (362), 3738 (262), 3295 (225), and 2338 (196) total (rain-related) fatal crashes over the study period. Except for a few other urbanizing counties, only counties around the four major metropolitan areas had more than 500 fatal crashes over the study period. As expected, more rain-related fatal crashes occurred in the wetter eastern part of the state due to the higher frequency of rainfall.

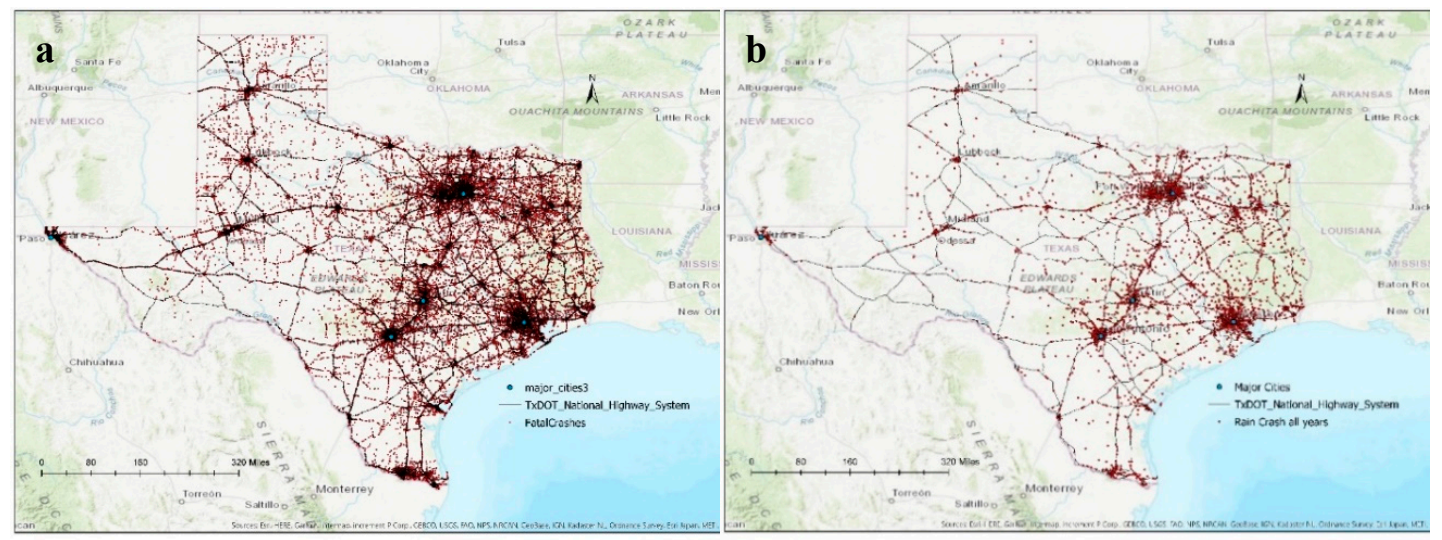

Figure 14. Spatial distribution of total (a) and rain-related (b) fatal crashes in Texas, 2001-2018.
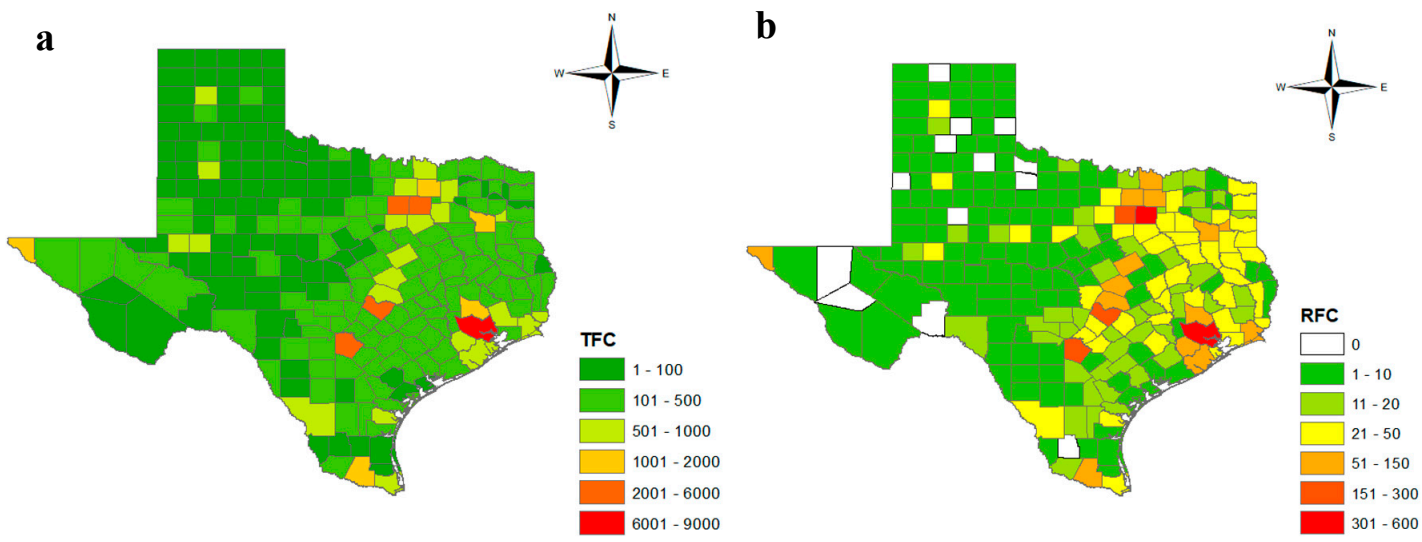

Figure 15. Spatial distribution of total fatal crashes (a) and rain-related fatal crashes (b) by county in Texas, 2001-2018.

The relative risk was also computed at the county level, as seen in Figure 16. The rainfall frequency (percentage of time it rains) based on gridded radar rainfall data, also shown in Figure 16, was used to compute the relative risk as explained earlier. It is clear that the relative risk is generally lower in the wetter regions of Texas-the eastern part. This can be because drivers are more familiar with wet 
conditions in these regions. This agrees with the observation of Elvik [54] that risk factors encountered more frequently have lower impact on transportation safety. It can also be seen in Figure 16 that the highly urbanized counties have lower relative risk than surrounding counties and that the western less populated counties have higher relative risk. This can be caused by the lower speeds in populated areas and small numbers of fatal crashes overall in rural counties, which will result in very high variability of the proportion of rain-related crashes. Other factors can also contribute to the differences in relative risk between urban and rural areas (e.g., [55]).
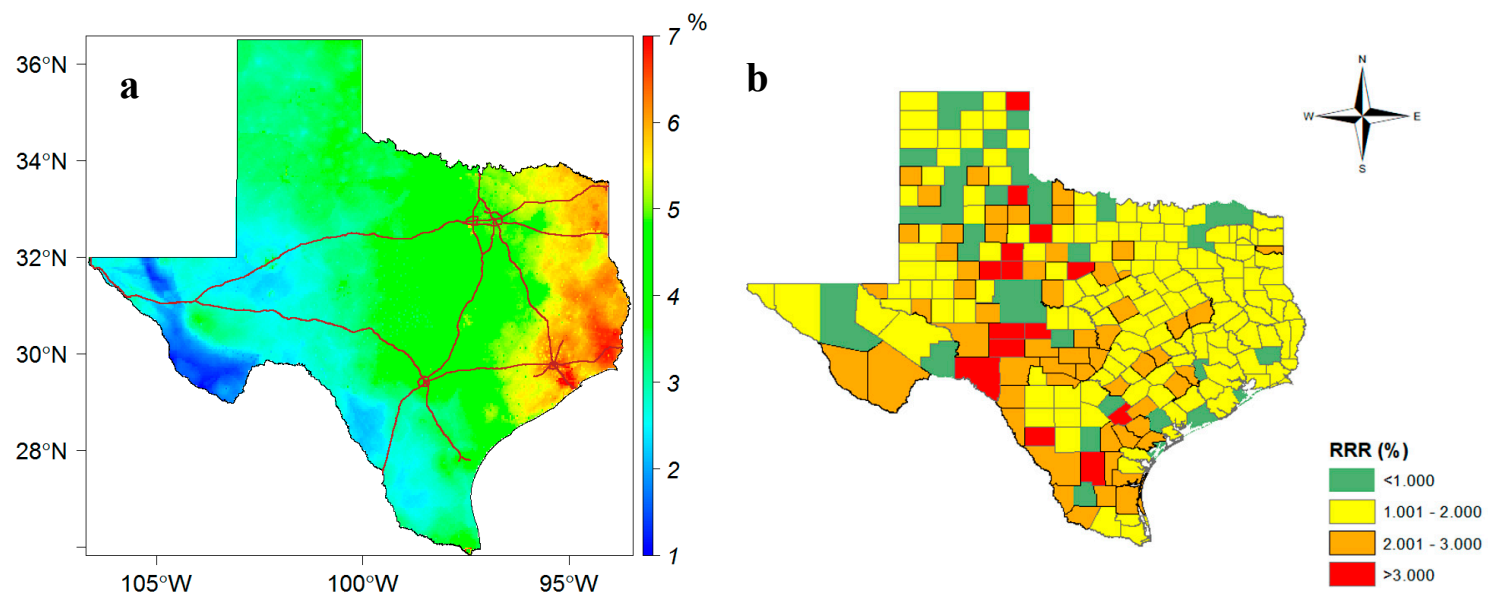

Figure 16. Spatial distribution of the rainfall frequency ( $\%$ of time it rains) (a) and the relative risk ratio at the county level (b).

\section{Discussion and Conclusions}

This paper presented a detailed statistical analysis of total and rain-related fatal crashes in Texas from 1994 through 2018 using data obtained from the FARS database maintained by the NHTSA. Descriptive statistics of rain-related fatal crashes were compared to those of total fatal crashes. On average, rain-related fatal crashes represent about $6.8 \%$ of total fatal crashes. However, the proportion shows higher variability at the annual, monthly, and hourly time scales and seems to be influenced by other factors such as the age and gender of the driver. Total and rain-related crashes show statistically significant decreasing trends when normalized by the total number of licensed drivers or vehicle miles travelled. The decreasing trends agree with the findings of other studies focused on other regions [56,57]. The decreasing trend may be related to improved road systems, which reduces the likelihood of crashes, improved crash worthiness of vehicles and population health, which enhance the crash survival rates [58], improved severe weather warning, and the application of intelligent transportation systems $[59,60]$.

As expected, rain-related crashes are strongly correlated with the total annual precipitation $(r=0.84)$. Interestingly, this is not the case for monthly data. The effect of temperature (through evaporation) was so strong that it reverses the relationship between precipitation and rain-related crashes since the summer months are wetter than the winter months. Moreover, precipitation during hot weather can cool the road surface, improving its frictional properties as a result. Summer precipitation is more episodic than winter precipitation, and persists for longer durations (more exposure). In addition, freezing rain situations present major hazards that increase crash occurrence during the winter months. The influence of temperature can also be observed when data is analyzed by the hour of the day, showing higher proportions of rain-related crashes in the morning hours. Both total and rain-related fatal crashes have three peaks, morning and evening rush hours and during the third $\mathrm{h}$ of the morning (bars in Texas close at 2:00 a.m.). Using high-resolution radar precipitation estimates, we quantified the relative risk of a fatal crash during rainy conditions compared to dry conditions. The relative risk was always greater than 1.0 at hourly, monthly, and annual time scales. However, it shows significant 
variability at the monthly (1.07 to 2.78 ) and hourly scales (1.35 to 2.57). The highest risk of a fatal crash due to precipitation occurred during the morning rush hour, although more rain-related fatal crashes occurred during the evening rush hour, most likely due to the effect of the temperature discussed above, which is also likely the reason that no evening peak is observed in the relative risk. Moreover, freezing conditions, although not common in Texas, are more likely to occur in the morning. As expected, most fatal crashes were clustered in major metropolitan areas due the higher traffic volumes while rain-related crashes occurred more in these areas and in the eastern part of the state, in general, due to the higher rainfall frequency. However, the relative risk was generally higher in rural and drier counties where rainy conditions are less expected and traffic volumes are lower.

As shown in many previous studies, male drivers involved in fatal crashes greatly outnumber females as males are more likely to be involved in risky behavior. Male drivers are about 2.57 times more likely to be involved in a rain-related fatal crash than female drivers, but the ratio is higher for all fatal crashes (2.85), which suggests that females are less likely to drive in rainy conditions. However, the proportion of females varies slightly for different age groups. Nearly half $(46 \%)$ of the drivers involved in fatal crashes were killed and the data suggests that female drivers are more likely to be killed than male counterparts if the crash is fatal. Young male and female drivers (age under 25 years) are more likely to be involved in a fatal crash for both crash categories, followed by male and female drivers in the 25- to 34-year age group. Young drivers have relatively lower driving experience and are more likely to take risks when they drive during precipitation. Drivers between 65 and 74 years old are the least likely to be involved in fatal crashes for both crash categories. The age distribution of drivers killed in fatal crashes suggests that older drivers, like female drivers, are more likely to be killed in a fatal crash than younger drivers if the crash is fatal.

The analysis described in this paper provides a first step towards such studies that must include detailed statistical analysis of all the factors that contribute to the occurrence and severity of rain-related fatal crashes. The study considered rainy conditions without considering rain that may have fallen earlier, thus impacting the road conditions, nor the fact that road surfaces continue to be wet after rainfall stops. It is likely that the relative risk will vary with the intensity and the duration of precipitation, both of which were not considered in the analysis. Highways and roads around urbanized big cities have higher traffic volumes, but we used total VMT values. Future research should focus on the spatial variability of the relative risk under rainy conditions. Lastly, Texas has a problem of un-insured, undocumented drivers. Nonetheless, we do not expect our results to have been affected by the small errors in the number of licensed drivers.

The immediate solution to driving under hazardous conditions, which increases the risk of a fatal crash or even any crash, is clear [60]. Roadway fatalities, injuries, and crashes can be substantially reduced when new vehicle safety technologies, such as available automatic emergency braking, lane departure warning, blind spot warning, and pedestrian detection technologies become more common. Actually, some studies expect the wide adoption of these technologies to cut crash fatalities by about $50 \%$ (e.g., Wang, 2019) [61]. Measures such as more supervised driving time in teen driver education programs and considering road design characteristics may significantly decrease crashes committed by young drivers. Severe weather education and more specific real-time descriptions of storm-hazard areas can also be very helpful. Finally, research is needed on how a viral disaster such as the COVID-19 outbreak would affect traffic safety in terms of traffic volume changes, rerouting, and evacuation during hazardous weather conditions, and the availability and effectiveness of emergency road services and health services.

Author Contributions: H.O.S. guided this research, contributed significantly to preparing the manuscript for publication, and developed the research methodology. Z.H. processed the data and developed the scripts used in the analysis. Z.H. prepared the first draft. H.O.S. performed the final overall proof reading of the manuscript. All authors have read and agreed to the published version of the manuscript.

Funding: The first author is funded through a scholarship from Chinese Scholarship Council (No. 201606300024).

Conflicts of Interest: The authors declare no conflict of interest. 


\section{References}

1. World Health Organization (WHO). Global Status Report on Road Safety 2018. December 2018. Available online: https://www.who.int/violence_injury_prevention/road_safety_status/2018/en/. (accessed on 8 September 2020).

2. Ariffin, A.H.; Hamzah, A.; Solah, M.S.; Paiman, N.F.; Hussin, S.F.M.; Osman, M.R. Pedestrian-Motorcycle Collisions: Associated Risks and Issues. In MATEC Web of Conferences; EDP Sciences: Les Ulis, Paris, France, 2017; Volume 90, p. 01066. [CrossRef]

3. Centers for Disease Control and Prevention. Travel by Air, Land \& Sea-Road \& Traffic Safety. In Health Information for International Travel; 2020 Edition (Yellow Book 2020); Centers for Disease Control and Prevention: Atlanta, PA, USA, 2020. Available online: https://wwwnc.cdc.gov/travel/yellowbook/2020/travelby-air-land-sea/road-and-traffic-safety (accessed on 4 September 2020).

4. Munteanu, P.L.; Rosu, M.; Panaitescu, V.; Punga, A. Human and Environmental Factors Contributing to Fatal Road Accidents in a Romanian Population. RJLM 2014, 22, 97-100. [CrossRef]

5. Pande, A.; Abdel-Aty, M. Discovering Indirect Associations in Crash Data through Probe Attributes. Transp. Res. Rec. 2008, 2083, 170-179. [CrossRef]

6. Hjelkrem, O.A.; Ryeng, E.O. Chosen Risk Level During Car-Following in Adverse Weather Conditions. Accid. Anal. Prev. 2016, 95, 227-235. [CrossRef] [PubMed]

7. Liu, C.; Chen, C.-L.; Subramanian, R.; Utter, D. Analysis of Speeding-Related Fatal Motor Vehicle Traffic Crashes Art. no. HS-809 839 2005. Available online: https://trid.trb.org/view/763754 (accessed on 29 June 2020).

8. Xu, C.; Wang, W.; Liu, P. Identifying Crash-Prone Traffic Conditions Under Different Weather on Freeways. J. Saf. Res. 2013, 46, 135-144. [CrossRef] [PubMed]

9. Kim, W.; Svancara, A.M.; Kelley-Baker, T. Understanding the Impact of Road Design Characteristic on Teen Driver's Fatality. Traffic Inj. Prev. 2020, 21, 313-318. [CrossRef]

10. Unrau, D.; Andrey, J. Driver Response to Rainfall on Urban Expressways. Transp. Res. Rec. 2006, 1980, 24-30. [CrossRef]

11. Saha, S.; Schramm, P.; Nolan, A.; Hess, J. Adverse Weather Conditions and Fatal Motor Vehicle Crashes in the United States, 1994-2012. Environ. Health 2016, 15, 104. [CrossRef]

12. Wang, Y.; Liang, L.; Evans, L. Fatal Crashes Involving Large Numbers of Vehicles and Weather. J. Saf. Res. 2017, 63, 1-7. [CrossRef] [PubMed]

13. Pisano, P.A.; Goodwin, L.C.; Rossetti, M.A.U.S. Highway Crashes in Adverse Road Weather Conditions. In Proceedings of the 24th Conference on International Interactive Information and Processing Systems for Meteorology, Oceanography, and Hydrology, New Orleans, LA, USA, 21-24 January 2008; p. 16.

14. Fultz, A.J.; Ashley, W.S. Fatal Weather-Related General Aviation Accidents in the United States. Phys. Geogr. 2016, 37, 291-312. [CrossRef]

15. Bergel-Hayat, R.; Debbarh, M.; Antoniou, C.; Yannis, G. Explaining the Road Accident Risk: Weather Effects. Accid. Anal. Prev. 2013, 60, 456-465. [CrossRef]

16. Khan, G.; Qin, X.; Noyce, D.A. Spatial Analysis of Weather Crash Patterns. J. Transp. Eng. 2008, 134, 191-202. [CrossRef]

17. Jackson, T.L.; Sharif, H.O. Rainfall Impacts on Traffic Safety: Rain-Related Fatal Crashes in Texas. Geomat. Nat. Hazards Risk 2014, 7, 1-18. [CrossRef]

18. Qiu, L.; Nixon, W.A. Effects of Adverse Weather on Traffic Crashes. Transp. Res. Rec. J. Transp. Res. Board 2008, 2055, 139-146. [CrossRef]

19. Andrey, J.; Mills, B.; Leahy, M.G.; Suggett, J. Weather as a Chronic Hazard for Road Transportation in Canadian Cities. Nat. Hazards 2003, 28, 319-343. [CrossRef]

20. Sun, X.; Hu, H.; Habib, E.; Magri, D. Quantifying Crash Risk under Inclement Weather with Radar Rainfall Data and Matched-Pair Method. J. Transp. Saf. Secur. 2011, 3, 1-14. [CrossRef]

21. Hambly, D.; Andrey, J.; Mills, B.; Fletcher, C.; Fletcher, C.G. Projected Implications of Climate Change for Road Safety in Greater Vancouver, Canada. Clim. Chang. 2012, 116, 613-629. [CrossRef]

22. El-Basyouny, K.; Barua, S.; Islam, M.T.; Li, R. Assessing the Effect of Weather States on Crash Severity and Type by Use of Full Bayesian Multivariate Safety Models. Transp. Res. Rec. J. Transp. Res. Board 2014, 2432, 65-73. [CrossRef] 
23. Milton, J.C.; Shankar, V.N.; Mannering, F.L. Highway Accident Severities and the Mixed Logit Model: An Exploratory Empirical Analysis. Accid. Anal. Prev. 2008, 40, 260-266. [CrossRef]

24. Anastasopoulos, P.C.; Mannering, F.L. A Note on Modeling Vehicle Accident Frequencies With Random-Parameters Count Models. Accid. Anal. Prev. 2009, 41, 153-159. [CrossRef]

25. Depaire, B.; Wets, G.; Vanhoof, K. Traffic Accident Segmentation by Means of Latent Class Clustering. Accid. Anal. Prev. 2008, 40, 1257-1266. [CrossRef]

26. Matkan, A.A.; Mohaymany, A.S.; Mirbagheri, B.; Shahri, M. Detecting the Spatial-Temporal Autocorrelation Among Crash Frequencies in Urban Areas. Can. J. Civ. Eng. 2013, 40, 195-203. [CrossRef]

27. Eisenberg, D. Detecting the Spatial-Temporal Autocorrelation Among Crash Frequencies in Urban Areas. Accid. Anal. Prev. 2004, 36, 637-647. [CrossRef]

28. Andrey, J. Long-Term Trends in Weather-Related Crash Risks. J. Transp. Geogr. 2010, 18, 247-258. [CrossRef]

29. Edwards, J.B. Weather-Related Road Accidents in England and Wales: A Spatial Analysis. J. Transp. Geogr. 1996, 4, 201-212. [CrossRef]

30. Andreescu, M.; Frost, D. Weather and Traffic Accidents in Montreal, Canada. Clim. Res. 1998, 9, $225-230$. [CrossRef]

31. Sangare, M.; Gupta, S.; Bouzefrane, S.; Banerjee, S.; Muhlethaler, P. Exploring the Forecasting Approach for Road Accidents: Analytical measures with Hybrid Machine Learning. Expert Syst. Appl. 2020, 113855, 113855. [CrossRef]

32. Oralhan, B.; Göktolga, Z.G. Determination of the Risk Factors That Influence Occurrence Time of Traffic Accidents with Survival Analysis. Iran. J. Public Health 2018, 47, 1181-1191.

33. Benlagha, N.; Charfeddine, L. Risk Factors of Road Accident Severity and the Development of a New System for Prevention: New Insights from China. Accid. Anal. Prev. 2020, 136, 105411. [CrossRef]

34. Abdel-Aty, M.; Pande, A. ATMS Implementation System for Identifying Traffic Conditions Leading to Potential Crashes. IEEE Trans. Intell. Transp. Syst. 2006, 7, 78-91. [CrossRef]

35. Ma, Z.; Shao, C.; Yue, H.; Ma, S. Analysis of the Logistic Model for Accident Severity on Urban Road Environment. In Proceedings of the 2009 IEE Intelligent Vehicles Symposium, Xi'an, China, 3-5 June 2009; IEEE: Piscataway, NJ, USA, 2009; pp. 983-987. [CrossRef]

36. Ma, Z.; Zhang, S.-R.; Wang, J. Analysis of Accident Severity on Chinese Two-Lane Rural Highways Using Multinomial Logit Model. ICTIS 2011, 693-699. [CrossRef]

37. Jung, S.; Qin, X.; Noyce, D.A. Rainfall Effect on Single-Vehicle Crash Severities Using Polychotomous Response Models. Accid. Anal. Prev. 2010, 42, 213-224. [CrossRef]

38. Wilson, F.A.; Stimpson, J.P. Trends in Fatalities from Distracted Driving in the United States, 1999 to 2008. Am. J. Public Health 2010, 100, 2213-2219. [CrossRef] [PubMed]

39. Lira, M.C.; Sarda, V.; Heeren, T.C.; Miller, M.; Naimi, T.S. Alcohol Policies and Motor Vehicle Crash Deaths Involving Blood Alcohol Concentrations Below 0.08\%. Am. J. Prev. Med. 2020, 58, 622-629. [CrossRef] [PubMed]

40. Jovanis, P.P.; Chang, H.-L. Modeling the Relationship of Accidents to Miles Traveled. Transp. Res. Rec. 1986, $1068,42-51$.

41. Amoros, E.; Martin, J.-L.; Laumon, B. Comparison of Road Crashes Incidence and Severity Between Some French Counties. Accid. Anal. Prev. 2003, 35, 537-547. [CrossRef]

42. Abdel-Aty, M.; Chen, C.L.; Radwan, A.E. Using Conditional Probability to Find Driver Age Effect in Crashes. J. Transp. Eng. 1999, 125, 502-507. [CrossRef]

43. Yan, L.; He, Y.; Qin, L.; Wu, C.; Zhu, D.; Ran, B. A Novel Feature Extraction Model for Traffic Injury Severity and Its Application to Fatality Analysis Reporting System Data Analysis. Sci. Prog. 2019, 103, 3685041988647. [CrossRef]

44. National Center for Statistics and Analysis. Fatality Analysis Reporting System (FARS) Analytical User's Manual, 1975-2018; National Highway Traffic Safety Administration: Washington, DC, USA, 2019.

45. National Highway Traffic Safety Administration. Traffic Safety Facts 2011 Data-Pedestrians. Ann. Emerg. Med. 2013, 62, 612. [CrossRef]

46. Li, G.; Baker, S.P.; Langlois, J.A.; Kelen, G.D. Are Female Drivers Safer? An Application of the Decomposition Method. Epidemiology 1998, 9, 379-384. [CrossRef] 
47. Kahane, C.J. Injury Vulnerability and Effectiveness of Occupant Protection Technologies for Older Occupants and Women. Art. no. DOT HS 811766 2013. Available online: https://trid.trb.org/view/1252398 (accessed on 21 July 2020).

48. Dong, Q.; Wang, C.; Xiong, C.; Li, X.; Wang, H.; Ling, T. Investigation on the Cooling and Evaporation Behavior of Semi-Flexible Water Retaining Pavement based on Laboratory Test and Thermal-Mass Coupling Analysis. Materials 2019, 12, 2546. [CrossRef]

49. American Society for Testing and Materials. ASTM Definitions of Terms Relating to Traveled Surface Characteristics. In Annual Book of ASTM Standards (E867); American Society for Testing and Materials: West Conshohocken, PA, USA, 2000; Volume 4, pp. 2-7.

50. Ghebreyesus, D.; Sharif, H.O. Spatio-Temporal Analysis of Precipitation Frequency in Texas Using High-Resolution Radar Products. Water 2020, 12, 1378. [CrossRef]

51. Black, A.W.; Mote, T.L. Characteristics of Winter-Precipitation-Related Transportation Fatalities in the United States. Weather Clim. Soc. 2015, 7, 133-145. [CrossRef]

52. Stevens, S.E.; Schreck, C.J.; Saha, S.; Bell, J.E.; Kunkel, K.E. Precipitation and Fatal Motor Vehicle Crashes: Continental Analysis with High-Resolution Radar Data. Bull. Am. Meteorol. Soc. 2019, 100, 1453-1461. [CrossRef]

53. Texas Demographic Center, Texas 2010 Census Data. Available online: https://demographics.texas.gov/ (accessed on 21 July 2020).

54. Elvik, R. Laws of Accident Causation. Accid. Anal. Prev. 2006, 38, 742-747. [CrossRef] [PubMed]

55. Andrey, J.; Hambly, D.; Mills, B.; Afrin, S. Insights into Driver Adaptation to Inclement Weather in Canada. J. Transp. Geogr. 2013, 28, 192-203. [CrossRef]

56. Farmer, C.M. Relationships of Frontal Offset Crash Test Results to Real-World Driver Fatality Rates. Traffic Inj. Prev. 2005, 6, 31-37. [CrossRef]

57. Farmer, C.M.; Lund, A.K. Trends Over Time in the Risk of Driver Death: What If Vehicle Designs Had Not Improved? Traffic Inj. Prev. 2006, 7, 335-342. [CrossRef] [PubMed]

58. Cheung, I.; McCartt, A.T. Declines in Fatal Crashes of Older Drivers: Changes in Crash Risk and Survivability. Accid. Anal. Prev. 2011, 43, 666-674. [CrossRef]

59. Sharif, H.O.; Jackson, T.L.; Hossain, M.; Zane, D. Analysis of Flood Fatalities in Texas. Nat. Hazards Rev. 2015, 16, 04014016. [CrossRef]

60. Omranian, E.; Sharif, H.O.; Dessouky, S.; Weissmann, J. Exploring Rainfall Impacts on the Crash Risk on Texas Roadways: A Crash-Based Matched-Pairs Analysis Approach. Accid. Anal. Prev. 2018, 117, 10-20. [CrossRef]

61. Wang, J.-S. Target Crash Population for Crash Avoidance Technologies in Passenger Vehicles, Art. no. DOT HS 812653 2019. Available online: https://trid.trb.org/view/1602884 (accessed on 21 July 2020). 